\title{
Civil War Risk in Democratic and Non-Democratic Neighborhoods
}

\author{
Clionadh Raleigh \\ Centre for the Study of Civil War, (PRIO) \\ University of Colorado at Boulder \\ World Bank Project on Political Institutions and Conflict
}

\begin{abstract}
This study questions the extent to which domestic conflict is influenced by national, regional, and international relationships. It is designed to answer specific questions relating to the effects of neighboring characteristics on a state's risk of conflict and instability: what is the interaction between neighboring conflict and political disorder? Do democratic neighborhoods have different conflict trajectories than non-democratic neighborhoods and if so, where and why? Given that most poor countries are located in poor and conflictual neighborhoods, to what extent is there a relationship between poverty and political disorder in different regime neighborhoods? Using spatial lag terms to specify neighboring regime characteristics and multilevel models to differentiate between explanatory levels, this study reiterates the importance of domestic and neighboring factors in promoting or diminishing the risk of instability and conflict. However, the pronounced negative effects of autocratic and anocratic neighborhoods are mitigated by a growing domestic GDP. This study also finds that democratic neighborhoods are more stable, regardless of income level. Research presented here is unique in its contribution regarding how regime type as a significant development indicator, which in turn is salient in determining the risks of civil war across states.
\end{abstract}

World Bank Policy Research Working Paper 4260, June 2007

The Post-Conflict Transitions Working Paper Series disseminates the findings of work in progress to encourage the exchange of ideas about post-conflict development (more information about the Post-Conflict Transitions Project can be found at http://econ.worldbank.org/programs/conflict ). An objective of the series is to get the findings out quickly, even if the presentations are less than fully polished. The papers carry the names of the authors and should be cited accordingly. The findings, interpretations, and conclusions expressed in these papers are entirely those of the authors. They do not necessarily represent the views of the World Bank, its Executive Directors, or the countries they represent. Policy Research Working Papers are available online at http://econ.worldbank.org. 


\subsection{Why Include Neighbors in the Study of Civil Conflict?}

Researchers are increasingly interested in identifying characteristics of a state's surroundings that have positive or adverse effects on peace and stability. To date, a number of studies have found that neighboring civil wars increase a state's risk of civil conflict (see Sambanis 2001, Gleditsch 2002 \& 2003, Hegre 2003). In addition, neighboring characteristics and relationships between states can alter the risk of civil conflict within a state (Gleditsch 2003, Murdoch and Sandler, 2002 Collier and Hoeffler, 2004). The heightened risk of civil war in some larger regions (e.g. Central Africa, West Africa) appears to be related to the limited abilities of weak states to control their unstable surroundings. This study aims to contribute to the literature explaining how spatially determined relationships influence domestic political processes and the risk of civil war.

Underlying this study is the assumption that domestic political phenomena are dynamic in that they vary over time and space. Further, these dynamics are influenced by national, regional and international relationships (see Enterline, 1998). As evidence of these dynamics and international influences, Gleditsch (2002) finds regional political characteristics have a stronger effect on both international war and civil war than domestic political conditions. Gleditsch (2003) concludes that democratic regions have a positive effect on peace within member states while autocratic and anocratic regions have a positive effect on conflict within member states. However, neighboring (border sharing) and regional instability have varying impacts on different countries over time and also interact with other salient factors important to civil peace. In short, depending on the state and region, neighboring political attributes influence civil war risk across states differently.

I will continue Gleditsch's line of study by arguing that the nature of neighboring regimes and instability impact the prospect of civil war onset and recurrence within a state. This study is designed to specifically answer the following questions: what is the interaction between neighboring conflict and domestic conflict rates? Do democratic neighborhoods have different conflict trajectories than non-democratic neighborhoods and if so, where and why? Given that most poor countries are located in poor and conflictual neighborhoods, to what extent is there a relationship between poverty and conflict onset and recurrence in different regime neighborhoods? I intend to answer these questions by focusing on the spatial relationships and interdependences of neighbors and states within regions. 
I address these questions by first discussing the current literature on international geopolitics and geography as it affects civil war onset and recurrence. With an attempt to extend past discussions of spatial dependence in civil war onset, I cover spatial dependence between causes of civil war, with particular emphasis on the nature of political institutions in neighboring states. Specifically, states within various types of political neighborhoods (democratic, autocratic, anocratic, low-income, high-income) may experience different effects due to neighborhood characteristics. Second, I hypothesize the ways in which spatial dependence and heterogeneity influence war risk. Third, I describe both the data and methods employed for the multi-level analysis undertaken. Fourth, I discuss the patterns and relationships uncovered by the analysis, remarking on how the interaction between regimes, income levels and neighborhoods is integral to understanding varying states' records of peace and conflict. Fifth, I conclude with a brief synopsis of how these results can inform conflict prevention and management strategies.

\subsection{How Do Neighbors Affect Risk Patterns of Civil Conflict and Political Disorder?}

\subsection{Bad Neighborhoods and the Clustering of Conflict}

It is clear that internal conflict clusters within and across states and within and across regions. The extent that such clustering is a result of conflict diffusion, spatially determined relationships, or the clustering of similar characteristics is debated (see Gleditsch 2003 and Hegre et al. 2001). The positive role neighboring war plays in inciting domestic conflict is evident in both qualitative and quantitative work. In certain cases, neighboring wars are seen as one complete war; the Congo war during 1996-2002 involved several neighboring states and prompted Madeline Albright, then US secretary of state, to claim it as “Africa's first world war" (New York Times, 02/06/00).

A growing body of work extends past clustering observations and considers the role of neighbors and regions in affecting domestic peace and political stability within states. There are several reasons why neighbors and neighborhoods may be relevant as a determinant of a state's

prospect for peace and stability. States typically interact more with immediate neighbors and may operate with similar economic, social and political institutions. Those states with conflict-prone characteristics may then cluster, and the resultant war risk may be independent. However, it is clear that neighbors and regions have an additive effect on internal and international war. The effects are additive in the sense that in peaceful zones, neighbors bolster traditions of peace (Gleditsch, $2002 \&$ 
Enterline, 1998); while neighbors in conflict prone zones contribute additional risk of war and instability (Raleigh, 2004 and Gleditsch, 2003).

In examining ways in which characteristics may compound domestic war risk, scholars have selected different attributes deemed most problematic. Examples include: shared ethnic groups across borders (Woodwell, 2001; Ngaruko and Nkurunziza, 2002; Lake and Rothchild, 1998); political institutions (Sambanis, 2001, Gleditsch 2001; Collier and Hoeffler 2004); refugee flows (Salehyan and Gleditsch, 2004); and economic institutions (Murdoch and Sandler, 2002; Collier and Hoeffler, 2004). Although the research surveyed has illuminated aspects of civil war risk previously unknown, certain aspects of neighborhood relations remain unclear and misspecified.

\subsection{Economic Impacts to Neighboring States}

Of particular salience to this study is how spatial 'spillovers' of conflict are the result of both the direct consequences of neighboring unrest and the indirect effects from characteristics of surrounding states. Studies of economic spillovers have established that civil wars in one country directly impact the economies of neighboring countries and beyond neighboring borders (Murdoch and Sandler, 2002:92). Collier and Hoeffler (2004:2) estimate that a civil war reduces the growth rate in surrounding countries by an average of $0.9 \%$ per annum. Furthermore, increased rates of military spending also adversely affect the surrounding economies (see also Collier and Hoeffler, 2002). This interaction across borders increases as the intensity of the war increases (2002:106). Direct or indirect economic impacts are of particular importance as GDP is often found to be the most significant indictor of civil war risk. Simultaneously, an unstable GDP may contribute to increased levels of political disorder, also disproportionately found in developing/low income states.

\subsection{Impact of a Democratic State on Democracy and Instability across Regions}

That stable and consolidated democratic institutions are generally pacific and limit the onset and spread of interstate war is argued by the democratic peace thesis and is often empirically confirmed (see. Gleditsch and Ward, 2000 and Enterline, 1998). Yet, however stable the dyadic democratic peace is, the debate on the internal stability of democracies is ongoing. Ellingsen and Gleditsch (1997) find that an inverted $U$ shape curve describes the relationship between regime type and civil conflict, which subsequently demonstrates the sustainably peaceful nature of coherent democracies and the association between anocratic regimes and conflict. Hegre (2003) upsets the accepted view of democracy's role in civil peace by exposing how democracies are stable only if embedded in 
developed economies. He argues that is due to three factors: 1) the impact of development on democratic stability; 2) differences in the resources required to handle conflict in autocracies and democracies; and 3) increased pressure to democratize from wealthy states. The relationship between democracy and development is demonstrated as mutually reinforcing--the higher the development, the more democracy lessens the risk of civil conflict; the more democratic a country, the more development reduces the risk of civil war (2003:232).

The relationship between democracy and civil war is considerably more complex than the positive relationship between peace (internal and regional) and democracy for interstate war (Gleditsch, 2002). Higher levels of domestic and regional democratization are associated with more peace, but instability in democracies is associated with higher levels of conflict such that it may counteract the benefits of democratization (2002: 109). Furthermore, and directly applicable to this project, Gleditsch finds that "democratizing states located among relatively democratic neighbors have significantly lower risks of experiencing civil war than do countries located in a zone of more autocratic and less constrained polities (2002: 109)."

Political consequences from neighboring states are therefore considerable. As Sambanis (2001) observes, stable democratic institutions are more important in ethnically charged societies or ethnically divided societies over states in which political opportunities and access to power are not framed in ethnic terms. He further posits that 'bad neighborhoods'- those defined by an absence of democracy- will have weak political institutions which "can only exacerbate political and economic grievances in other countries as a result of the uncontrolled domestic ethnic antagonisms" (2001:268). Sambanis concludes that neighborhood democracy competes with internal political structures for influence on peace (2001:275). This is in line with Gleditsch's (2002) discussion concerning the equal importance of external characteristics in civil war risk assessment.

\subsection{Stability of Regime Types}

The rate and nature of regime diffusion indirectly influences the risk of war within states. Cederman and Gleditsch (2004) contend that evolutionary mechanisms of natural selection and adaptation can explain the increase and diffusion of democracy and peace. Democratic regions are built on the local diffusion of democracies, which in turn produce the diffusion of the democratic peace, even with few regimes. Further, despite the adverse environment there might exist for lone democracies in a region, the "geographic clustering due to adaptive regime change can make it easier for democratic 
states to survive in a hostile, non-democratic environment" (2004: 604). The role of regime type in the creation of zones of peace notwithstanding, the clustering and diffusion of regime types is increasingly accepted. Both democratic and autocratic regimes have been shown to diffuse and cluster over time- regional change and regional regime characterization is pronounced. O'Loughlin et al state "geographic distance does not have much effect on the overall distribution of democracy scores, with the values of polities strongly correlating with the values of all neighboring states in the region" (1998: 563). Starr's (1991) study tests whether regime diffusion would match pronounced interstate war diffusion patterns. His finding that "in the study of war, we found significant neighbor effects, whereby the activities of bordering states had contagious effects (both emulative and infectious)" (1991: 362) is in line with his finding that state regime types were affected by neighboring, regional and global influences.

It should be noted that a number of authors have found no relationship between specific regime types and increased levels of conflict or peace (Fearon and Laitin 2003; Collier and Hoeffler 2002; Benson and Kugler 1998). This is perhaps due to data differences rather than theoretical differences, as it is evident that fully democratic and autocratic states and regions are more peaceful, whereas unstable and anocratic areas are clearly not.

Instability within states refers to the upset of political and governing systems, either toward a more democratic, autocratic or anocratic system. Political instability is a generally accepted indicator and instigator of civil unrest. That such volatility creates a more fertile climate for civil conflict is an established empirical conclusion. Mansfield and Snyder (2002) find that a transition from an autocratic regime to a partially democratic (anocratic) one is associated with a heightened war risk. Moreover, the transition toward democracy is "significantly more likely to generate hostility than the transition toward autocracy" (2002:298). Hegre et al. (2001) question whether the finding that anocratic regimes are positively related to conflict is, in fact, distinct from instability. Their proposition that both anocratic regimes and instability increase the risk of civil conflict in distinct and separate ways is upheld. Further, anocracies are still conflict prone when accounting for instability.

Whether unstable regimes and anocracies cluster has not been analyzed. From Hegre (2003) we recognize that both are distinct manifestations of political disorder and both are positively associated with conflict onset. Yet, it is unclear whether neighboring instability and/or neighboring 
anocracy specifically influence a state's risk of either civil war onset or political disorder. If spatially dependent relationships exist, neighboring regime characteristics should possess greater influence than states some distance away and equal to that of domestic considerations, as had been shown for other neighboring political attributes on civil war.

\subsection{Does the Risk of Conflict Recurrence vary across Regime Neighborhoods?}

A risk profile of civil war prone states based on internal and neighboring characteristics cannot ignore the considerable influence of the conflict trap. A state runs a $44 \%$ risk of returning to civil war up to five years after the cessation of the previous conflict (Collier et al., 2004: 83). The pathdependent effects of conflict, and the dynamics that evolved during a war, may lead to differential rates of recurrence across risk-prone states (Doyle and Sambanis, 2000). The risk of recurrence has been shown to be strongly related to political and economic advancement (Walter, 2004). It stands to reason that the political institutions both within and across states are of particular importance in creating a stable post-war environment, or alternatively, creating an environment of hostile and unstable relations which may exacerbate the already feeble governing institutions in a state.

However, it is also true that factors affecting the risk of recurrence are different from those across all civil wars. The airing of grievances and the cessation of conflict creates new opportunities for reinstated or new governments to redress the causes and consequences of the previous conflict. A failure to do so is presumed to lead to quick recurrence. Post-conflict third-party intervention is often couched in terms of improvements in political participation, as this factor particularly is important to post-conflict societies (Doyle and Sambanis, 2000). The lack of democratic institutions, which is generally insignificant in many onset studies, is shown by Walter to powerfully predict recurrence (2004: 384). Walter also finds the risk of recurrence is due to growth experienced in the interim between the cessation of conflict and the onset of another; should people believe their lot is not improving, rebel recruitment prospects improve (2004:372, Elbadawi, 2001, Collier and Hoeffler, 2001; Fearon and Laitin, 2003; Gates, 2002).

If internal political factors essentially make or break the conflict trap, the political environment in which a state is operating should have a considerable impact on its ability to hinder renewed conflict activity, for two separate reasons: 1) surrounding regime characteristics create a context in which neighboring intervention is harmful to continuing peace or where states are unable to withstand the negative implications of 'bad neighborhoods' due to a weakened postwar state; 
relatedly 2) "predatory states that seek to take advantage of the internal weaknesses of others" (Lake and Rothchild, 1998:5) can capitalize on the post-war weakness of states to encourage or fund a renewed rebellion.

\subsection{Hypotheses}

In an effort to build upon the multiple studies discussed above, I will integrate the various conclusions reached concerning conflict, regimes, regions and development. It is clear that regime neighborhoods/regions are associated with a particular risk structure for both interstate and intrastate conflict. Democratic areas have a positive impact on peace, while autocratic and anocratic areas have negative impact on peace. It is unclear whether these relationships consider a singular state's regime type, although democratic regions are found to have a pacifying effect on its member states. While democratic states in autocratic regions may be more conflict prone in the short term, due to the adaptive diffusion of democracies, democratic values result in long-term peace. But these relationships may be dependent on a state's level of development. The local and regional diffusion of democracy has, as Gleditsch $(2002,2003)$ has shown, a pacifying effect on civil conflict, but only at certain levels of income (Hegre, 2003) and only after an initial turbulent period. Further, researchers have separately shown the impact of neighboring wars and characteristics on the risk of internal strife, yet how these attributes affect a state's political stability is unknown.

I contend the effects of regime type and regime clustering can be further compartmentalized beyond broad meso (neighborhood) or macro (regional) levels; neighborhood regime types may affect clusters of high and low conflict risk states differently. Further, within high risk states, recurrence episodes will be treated separately to both retest Walter's findings on a larger population and determine the influence of surrounding states of the risk of political breakdown and conflict.

The following are four hypotheses regarding both civil war and regime characteristics. The first reasserts the claim that lagged neighboring war increases the risk of civil conflict within a state. The second makes distinctions between the varying influences of neighboring political institutions. The third assumes that the relationships specified in hypothesis two should be conditional on income. The fourth asserts that neighboring institutions and income should be strongly related to civil war recurrence.

\section{Hypothesis 1:}

As noted, the role of warring neighbors is acknowledged to positively affect civil war onset in a state. 
However, many well known studies often do not include this variable (e.g. Fearon and Laitin 2003). As a departure from other studies, I contend that the effects of neighboring wars differ across states, with high risk states experiencing compounding high risk due to neighboring states. Low risk states will experience a corresponding lower risk due to the general absence of neighboring civil wars.

Hypothesis 2: Neighborhood (border sharing states) regime characteristics influence the risk of civil war within a state.

2a) a "democratic" neighborhood will minimize the risk of civil war due to the pacifying nature of clustered democracies and the push in democratic states to not associate nor support autocratic and warring neighbors, regardless of a state's regime type. However, democratic states will display an additional peace 'dividend' over autocratic or anocratic members of democratic neighborhoods.

2b) an "autocratic" neighborhood will have no discernable effect on the risk of civil war onset regardless of a member state's regime type. There is no 'autocratic peace', autocrats may be more hostile to each other and generally not regard peace as a goal in neighboring states.

2c) an "anocratic" neighborhood will increase the risk of civil war for both anocratic and non-anocratic member states. The risk to all regime types may is positive, although anocratic and autocratic states may have a compounded risk due to internal political weakness or dissension. Externally, weak anocratic neighbors make them unable to coerce neighbors into peaceful behaviour or act as a stable intervener.

Hypothesis 3: Given that Hegre (2003) found that the positive relationship between democracy and civil peace is contingent on income levels, it is possible that neighboring influences are also related to income. At higher levels of development, hypothesis \#2 holds, yet at low levels of development the actions and effectiveness of neighboring democracies should be curtailed. Here, 'income' refers to the state's income, not the average of neighboring states.

3a) low income states in a democratic neighborhood will have a positive relationship to the risk of civil strife due to the inability of low income states to maintain significant control over potential rebellion within their borders and beyond.

3b) low income states in an autocratic neighborhood should not act in a considerably different way toward neighbors from high income autocracies. 
3c) anocratic neighborhoods are low income phenomena. Therefore, no discernable impact across income levels should be obvious.

Hypothesis 4: Hypothesis three relates to the ability of neighboring attributes to influence the risk of recurrence of conflict within a state. Because the risk of recurrence is strongly related to political factors within a state, the influence of interactions between political entities and their surrounding states may be heightened. Interactions across income levels and political institutions should be particularly important as they note the propensity of outside interference and domestic stability.

4a) All types of regimes within democratic neighborhoods should have a lower conflict risk, relative to other regime neighborhoods. Democratic states in democratic regions should have the lowest recurrence risk. Although lower income states should have an increased risk compared to higher income states.

4b) All regimes in autocratic neighborhoods should experience risks higher than those in democratic neighborhoods. This effect should be exacerbated by very low income levels. Autocratic or anocractic regimes in these neighborhoods should experience the highest risks.

4c) All regimes in an anocratic neighborhoods should experience their highest average risk of recurrence overall all other neighborhoods. This should be highly conditional on income, leading to the highest risks in the lowest income states, and a null effect in higher income states.

Across all hypotheses, I expect the strength of wars and regime effects to differ across countries. Nominally lower risk states may experience a marked decrease in the negative influence from neighbors. It is possible that such lower risk states may experience a positive 'dividend' from neighboring democracy and that the interaction between higher income democracies may create another type of democratic peace (in this case, civil peace).

\subsection{Data and Research Design}

Data for this project are based on both country-year data from Fearon and Laitin's Ethnicity, Insurgency and Civil War Project (2003) 1 and the PRIO/Uppsala Armed Conflict Data (P-UACD). The data are from 1946 to 2001 in country year format. In total, 161 countries with populations over 100,000 are included for 6820 country year observations.

The hypotheses call for two dependent variables. The first is civil war onset. Fearon and Laitin (2003) use a 1000 death threshold in their study while P-UACD has a 25 death threshold for

\footnotetext{
${ }^{1}$ Paper and data available at http://www.stanford.edu/group/ethnic/
} 
civil war. With the use of P-UACD data, I increase the number of conflicts accounted for by $28 \%$. For the period 1946-2001, 249 onsets are recorded using a two year hiatus from reported fighting to define a new onset. These onsets account for 3.6\% of the dataset. The recurrence variable is coded ' 1 ' for every subsequent war after the cessation of the first civil war within an independent state. A variable for peace years counted the years since the cessation of a conflict, initial or recurrent. There are 97 episodes of recurrent conflict in these data, accounting for $1.5 \%$ of the total data. Approximately $40 \%$ of all conflict onsets are recurrent wars. Considerable regional differences in the number of recurrent war episodes are apparent (see Table 3.1), but for the eight larger regions specified $^{2}$, still almost $40 \%$ of all civil wars across regions are recurrent.

Walter's (2004) study of recurrence using Correlates of War data found no consistent pattern in the timing of renewed war and a median duration of peace at 14 years. The P-UACD recurrence data display two distinct patterns: 1) these data show that the median duration of peace is between four to five years. As Collier et al (2004) note, most conflicts recur within a one to five year period after civil war has ended; 2) the most war prone period is between two and three years after initial cessation.

\section{Table 1: Conflict Onsets and Recurrence by Region ${ }^{3}$}

\begin{tabular}{|l|l|l|l|}
\hline Region & \multicolumn{2}{|l|}{} \\
\hline & Onsets (\#) & Subsequent Conflict (\#) & \% of Subsequent Conflicts \\
\hline Europe & 20 & 8 & $40 \%$ \\
\hline Middle East & 27 & 8 & $30 \%$ \\
\hline East Asia & 6 & 2 & $33 \%$ \\
\hline South/Central Asia & 37 & 14 & $38 \%$ \\
\hline South East Asia & 32 & 16 & $43 \%$ \\
\hline South/Central America & 39 & 14 & $41 \%$ \\
\hline Africa & 86 & 34 & $40 \%$ \\
\hline Oceania & 2 & 1 & $50 \%$ \\
\hline
\end{tabular}

\footnotetext{
${ }^{2}$ Regions specified include Europe, Middle East, East Asia, Central and South Asia, South East Asia, South and Central America, North America, Africa, and Oceania.

${ }^{3}$ North American region not included as it had no conflicts.
} 


\subsection{Domestic Variables}

The core variables used in this analysis are common throughout civil war onset studies. POLITY scores (from the POLITY dataset4) range from -10 to +10 . In total, $36 \%$ of the dataset consists of democratic country-years ( +5 to +10$), 43 \%$ of these data are autocratic country years $(-5$ to -10$)$ and $20 \%$ are anocratic country years $(-4.9$ to +4.9$)$. GDP data are from the Fearon and Laitin data. This variable is logged for analysis. Low income states are defined as those in the lowest quartile (under 1000 dollars per year). Moving averages are created for both Polity and logged GDP scores to create a smoothed trend surface and reduce the impact of single year outliers. Moving averages control for the need to lag particular variables and decrease the bias of large, sudden changes in scores. Values were smoothed at three year intervals.

Ethnic fractionalization data are from Fearon's Ethnic Fractionalization score (2002)5. This score has a high correlation (.75) with the commonly used Ethnic Fractionalization score derived from Atlas Narodov Mira (1964). The differences are primarily in the typology of groups, Fearon allows for ethno linguistic and cultural groups, whereas the Russian Atlas is based solely on ethno linguistic fractionalization. Table 3.2 summarizes the primary state level independent variables (table 3.2 presented in appendix).

\subsection{Neighbor Variables}

Spatial lag variables account for neighboring characteristics. Neighbors are first-order (direct border sharing) states and all neighborhood variables are averaged from first order values. Neighboring wars are coded positively (1) if a border sharing neighbor is at war (not limited to the year of onset but the duration of the neighboring war). This variable is further disaggregated by the size of the adjacent war. If the war intensity is coded as level 3 in the UACD it is considered a large war (similar to Fearon and Laitin's coding of onsets). Any level 2 conflict (more than 25 and less than 1000 battle deaths over the entire conflict) or a level 1 (25 battle deaths in one year, 1000 battle deaths over the course of the conflict)6 are subsumed under the small war category. It is then possible to check whether it is the presence or the size of a neighboring conflict is the salient attribute. A total of 2207 country years are coded ' 1 ' for the presence of a neighboring war. When

\footnotetext{
${ }^{4}$ http://www.cidcm.umd.edu/inscr/polity/

${ }^{5}$ http://www.duke.edu/web/licep/6/fearon/fearon.pdf
} 
neighboring wars are parsed based on war size, 1603 country years of states have neighbors with a small civil war, 1089 country years of states have a neighbor(s) experiencing a large civil war. An added total of 2692 neighboring country years is 485 country years higher than the neighboring war variable due to the presence of country years in which states had multiple neighbors suffering from both small and large wars. Table 3.2 summarizes independent neighboring variables.

Neighboring Polity scores are an average of all Polity scores across border sharing states. This variable has a median value of -1.5 . Democratic, autocratic and anocratic neighborhoods are dummy variables based on the average Polity score (consistent coding criteria as used for state democracy, autocracy and anocracy scores). In total, $16 \%$ of state country years are democratic neighbors, $25 \%$ are autocratic neighborhoods and 57\% are anocratic neighborhoods. The principal difference between neighborhood regime scores and state regime scores concerns the averaging of neighborhood polities. It does highlight a number of important considerations: fully democratic neighborhoods are the least likely phenomena, while anocratic (or mixed regime neighborhoods) clearly dominate. From the regressions results, it will be possible to note whether increasingly democratic regions or increasingly autocratic regions experienced more conflict.

Neighboring instability is a dummy variable and positive (1) if the overall average polity score moves by one unit (one point) from one year to the next. The degree of change is smaller in this instability measure due to the change required to move an average collective neighboring sum by one point.

To test the relationship between development and neighborhood influence, a series of interaction terms are created. Democratic neighborhoods are the reference category for the regime neighborhood variable. Interactions with income combine the logged GDP measure with regime dummy variables. All results must be considered relative to mean income states in democratic neighborhoods.

\subsection{Regional Characteristics and Variables}

For both theoretical and empirical reasons, countries are clustered into one of eighteen larger regions to test whether regional characteristics have an effect on conflict and political disorder. These regions are based on UN definitions of sub-continent regions. A considerable body of work

\footnotetext{
${ }^{6}$ See Strand et al. (2004) at http://www.prio.no/cwp/armedconflict/current/codebook_v3_0.pdf for more details on UACD coding practices.
} 
has focused on the region as an important political unit as the inclusion of regions can increase the information attained from analysis. Gleditsch (2002) examines the impact of regional institutions on both conflict and cooperation. As there is a marked regionalization of civil conflict, he concludes that this is a result of dependence and shared influences between geographically proximate entities. In turn, geographically determined interaction strongly influences the constraints and opportunities available to individual states, such as how states can control the influence of external events.

Differing concepts of 'region' are apparent within war literature. Varynen (1984) discusses how regional definition can depend on economic, political or social constructions and follows that war risk differs depending on which regional construction is predominant. Huntington bases his thesis of a Clash of Civilizations on regions defined by religious character; Cohen (1963) bases his regions on geopolitical relationships. Cohen's geopolitical regions are extended throughout the world to emphasize the importance of state and regional relationships to global security. His design of security is collective in that the local realities are considered part of overall global security. Rosh's (1988) concept of the security web emphasizes the importance of regional configurations in Third World state security. Security webs are primarily determined by geographical proximity and reflexive relationships between military spending and neighbor military spending. Rosh finds that a Third World state's immediate external environment has a significant impact on that country's military burden. Furthermore, Third World states are "uniformly affected by that state's immediate external environment while the particularities of a state's geographic region serve to shape the policies differently (1988: 692).

Keeping with the guidelines laid out by Thompson in his discussion of regional attributes, the foremost criterion for regional relationships is "proximity or primary stress on a geographic region" (1973: 93). Furthermore, "whereas analytical boundaries are ultimately arbitrary, some are most justified and more useful than others" (1973: 91) and the analyst should select the configuration that appears to offer the best understanding of the phenomena being studied. For this analysis, regions are based on United Nations definitions of regional subsystems clearly defined by the geographical proximity between member countries. This regional configuration is manipulatible and surely will result in different outcomes should it be changed, but as the international community recognize these regional configurations and states locate themselves within these regions, they are germane units of association. 


\subsection{Multi-Level Models}

A brief introduction to the choice of method is necessary. Previous civil war studies have used a variety of methods such as Poisson, linear, and logistic regression (Collier, 1999-2001; Fearon and Laitin, 2003; Sambanis, 2001). Fearon and Laitin's use of logistic regression is structured to provide probabilities of a positive outcome (e.g. probability that war will occur) yet it is not appropriate for time dependent data. Because of the nature of time-series data, observations of countries over time are dependent; not accounting for this temporal dependence can bias statistical models.

Mixed multilevel models (MML) can be used to explore and predict factors that lead to civil war onset and instability. MML models are a variant of multiple regression that allow for both random and fixed effects and a hierarchical distribution of variance. The basic idea of MML models is that both individual and group aspects explain the dependent variable (Sniders and Bosker, 1999). To ignore clustered relationships (such as pupils in schools, patients in hospitals, and country years in countries) risks overlooking the impact and importance of group effects while also potentially invalidating many of the traditional statistical techniques used for studying relationships. The basic MML model, described in equation 1, is designed around random intercepts. The intercept is able to vary throughout the levels producing a deviation of each level. In turn, this deviation is used to create the variance accounted for on each level. The benefits of using multilevel models are: 1) that hierarchical frameworks "encourage a systemic analysis of how covariates affect an outcome variable"; 2) correct biases in parameter estimates common in clustered data; 3) correct standard errors, confidence intervals and significance tests; 4) create decomposed variance and covariance for each level (Guo and Zhao, 2000: 444). The assumptions underlying MML models are that the variance on each level is higher than zero and the log relative risk follows a normal distribution (Langford et al. 1999).

For this model, observations are clustered into three levels. The level one units are country-

years (e.g. each year from 1945-2001 in France, Mali from 1960-2001, etc). Each country-year is associated with a country, which is nested in a region. 


\section{Equation 1: Multilevel Model with a Random Intercept- Three levels}

$$
\begin{aligned}
& Y_{i j k}=\beta_{00}+\beta_{10} x_{i j k}+e_{i j k}+u_{0 j k}+v_{0 k} \\
& \beta_{0 j}=\beta_{00}+u_{0 j} \\
& \beta_{0 k}=\beta_{00}+v_{0 k}
\end{aligned}
$$

$Y_{i j k}$ is the dependent variable- a function of both individual and group aspects (Sniders and Bosker, 1999: 39). $\beta_{00}$ is the intercept for this model. A basic multilevel model allows the intercept to be random. In that case, $\beta_{00}$ would represent the grand mean intercept. $X_{i j k}$ is the independent variable (such as GDP) and its effects on levels 1,2 , and $3\left({ }^{i j k}\right.$ respectively). ${ }^{u_{0 j k}}$ is the unmodeled variability on level 2 , and ${ }^{v_{0 k}}$ is the unmodeled variability on level three. These parameters exist for all higher levels $(2,3, \ldots \mathrm{n})$ and record the level deviation from the grand mean (Guo and Zing, 2000, 445). $\beta_{0 k}=\beta_{00}+u_{0 j}$ represents the addition of the grand intercept and the level 2 unit's deviation from it. $\beta_{0 k}=\beta_{00}+v_{0 k}$ represents the level 3 unit deviations plus the intercept. Without $u_{0 j k}$ and $v_{0 k}$, this would be a standard regression model. Together, these error terms make up a three level model, with three sources of deviation (e, u, \& v).

Multilevel models for binary data are similar to the models above except for the outcome variable. Due to the nature of dichotomous outcomes, the probability of a positive response " 1 " is equal to $P_{i j k}=\operatorname{pr}\left(Y_{i j k}-1\right)$. Using the GLM logit link function, the multilevel random intercept equation transforms into a logistic three level regression (Guo and Zhao, 2000: 446) where the outcome $Y_{i j k}$ is now a logistic term $\log \left\lfloor p_{i j k} /\left(1-p_{i j k}\right\rfloor u_{j}\right.$ has an expected mean of zero and variance of $\sigma_{u}^{2} ; v_{k}$ has an expected mean on 0 and a variance of $\sigma_{v}^{2}$.

A central benefit to using MML models is the ability to access level deviations. It is possible to calculate the proportion of variance explained by each level, also called an Intraclass Correlation 
Coefficient (ICC). This is the basic measure for the degree of dependence between observations and the proportion of variance accounted for by the group level, or the covariance of error terms inside a cluster. This proportional variance is found for higher levels $(2,3 \ldots \mathrm{n})$ by dividing the variance explained on level $\mathrm{x}$ by the sum of all levels of variance in the model. A percentage of variance explained by each level is found by multiplying this result by 100 . This percentage tells how much of the variance found in the dependent variable is due to the differences between higher units (Boardman, 2003). A high variance explained on the state level would imply that states differ significantly on their observations of the dependent variable; a low variance explained would imply that states are similar in how the causal variables affect the onset of civil war. A high variance explained on level three would imply that the effects of the independent variables upon the dependent differ over regions; therefore, heterogeneity exists among regions. A low variance explained implies that differences in regional variance based on independent variables are similar. With the addition of state or regional variables (e.g. a regional ethnic fragmentation score) we can note whether the corresponding level variance decreases. For example, an ICC of .10 would imply that $90 \%$ of variance across level 2 (ex. classes) observations of the dependent variable is due to level one (ex. students), while $10 \%$ is due to class differences.

\section{Equation 4.2: Estimating Intraclass Correlation Coefficients}

$$
\rho=\sigma_{u}^{2} /\left(\sigma_{u}^{2}+\sigma_{v}^{2}+\sigma_{e}^{2}\right)
$$

$=$ Variance due to the clustering variable / (variance due to the clustering variable + variance for all other levels).

For rare events data (used for civil war onset models), $\sigma_{e}^{2}=\pi^{2} / 6$ is the equation that estimates the level one logistic distribution (representing the variance on level one). For a standard logistic distribution (used for Uppsala/PRIO civil war onset models) $\sigma_{e}^{2}=\pi^{2} / 3$ is the equation to estimate the intra-class correlation coefficient and represents the variance on level one (Rabe-Hesketh et al, 2004). 
Equation 4.3: Multilevel Model with Random slopes and Binary Outcome- Three Levels

$$
\begin{aligned}
& \log \left\lfloor p_{i j} /\left(1-p_{i j}\right)\right\rfloor=\beta_{0 j k}+\beta_{1 j} x_{i j} \\
& \beta_{o j k}=\beta_{0 k}+u_{0 j k} \\
& \beta_{1 j}=\beta_{1}+u_{1 j} \\
& \beta_{0 k}=\beta_{0}+v_{0 k}
\end{aligned}
$$

The MML models with random coefficients are also known as the 'random slopes' models. Each random coefficient can vary over all levels to produce a unique variance for each unit. Therefore, ${ }^{u_{j k}}$ and ${ }^{u_{1 j}}$ represent the level two varying intercept and level two varying slope, respectively. $u_{1 j}$ is recorded for each level two unit as the unique deviation of the slope from the overall mean of the slope. The interpretation for higher-level units is the same. A covariance term is also created to indicate the effect of a varying coefficient on already highrisk categories.

\subsection{Interpretation of Regression Results}

\subsection{Civil War}

Whether multilevel models are an appropriate choice for the data is determined by an empty model (see Table 2). In this case, an empty model for onset shows a significant variance across second level observations (countries). If regions remain significant with the inclusion of independent variables we can conclude that 1) conflicts do cluster regionally regardless of similar controls; and 2) the regions chosen for this project are acceptable. Regions were not significant once neighboring attributes were added to models of civil war onset and recurrence, and therefore are excluded from further analysis. An empty model for recurrence shows considerable variation on the country level, but not the regional. This translates to mean that both all episodes of civil war and recurrent episodes have a particular geography in which they appear cluster over space and time. However, the empty models find that recurrence episodes cluster significantly more across states. 
Table 2: Empty Models for Dependent Variables

\begin{tabular}{||l|l|l|l|l|l||}
\hline \hline Dependent Variable & Constant & St. Error & $\begin{array}{l}\text { Log } \\
\text { Likelihood }\end{array}$ & Variance at level $2^{*}$ & Variance at level 3* \\
\hline Civil War Onset & -3.67 & .123 & -1028 & $.988(.215)$ & $.525(.239)$ \\
\hline & -3.85 & .191 & -1021 & $.669(.186)$ & $1.17(.413)$ \\
\hline Recurrent Civil war & -4.79 & .213 & -494 & $.940(.384)$ & $.177(.224)$ \\
\hline & -4.80 & .235 & -494 & & \\
\hline
\end{tabular}

${ }^{*}$ standard errors are reported in parenthesis

Table 3 compares the effects of the spatial lag conflict variables, specifically of neighboring war size on domestic civil war risk. Although bivariate regressions are presented in Table 3, it fully supports the hypothesis that neighboring wars exert a positive effect on the risk on domestic civil war inside a state. Further, the variance at level 2 imply those risks are experienced differently across countries as some experience an additional risk due to persistently warring neighbors, and other have a positive effect due to peaceful neighbors.

Table 3: Neighboring War Effects on Domestic Civil War Risk

\begin{tabular}{||l|l|l|l|l|l||}
\hline \hline Civil War Onset & Constant & Coefficient & St. Error & Log Likelihood & Variance at level 2 \\
\hline Large Wars & -3.73 & $.306^{* * *}$ & 0.182 & -1027.3 & $1.04(.24)$ \\
\hline Small Wars & -3.83 & $.562^{* * *}$ & 0.16 & -1022.81 & $1.03(.24)$ \\
\hline All Wars & -3.93 & $.668^{* * *}$ & 0.159 & -1020.18 & $1.03(.24)$ \\
\hline
\end{tabular}

Results for civil war onset (Table 3-model 1) reinforce previous assertions made within the literature. Counter to a number of studies, when Polity scores are transformed into a moving average, the salience of the score decreases and both Polity and its squared term are insignificant. This may be related to the nature of moving averages - the sudden peaks or lulls in scores will not exert undue influence when averaged over time (in this case, 3 years). Neighboring wars, instability, increased ethnic fractionalization, national population, oil dependence, and rough terrain all foster an environment for civil war. Specifically, the presence of a neighboring war increases the risk of internal conflict by 39\%. Increased income is the sole negative influence on the risk of civil war within a state. The intraclass correlation coefficient for model 2 (Table 4) is $.335-9 \%$ of the variance in civil wars is attributed to the country level (unmodeled variance). It can be understood as the percent of unexplained variation that is unique to states (Boardman and Saint Onge, 2004): 91\% of the variance in civil war onset occurs between country-years, while $9 \%$ of the total variation 
occurs across states. While in empty models, the ICC was considerably larger across states, it changes precipitously in some cases when independent variables are added. The ICC is each state's additional variance as computed by this specific model, or the change from the grand mean associated with each state. Increased or decreased variance is partially determined by individual risk. Those countries with increased variance were overwhelmingly low income, high risk countries. Such countries experience a higher risk of civil war and have neighbors at a higher risk. These states experience 'double jeopardy', particularly if a neighbor is actually at war. However, those states with a decreased variance are safer both due to internal characteristics and peaceful neighbors. They, in effect, have a peace dividend.

It is also clear (Table 5.3-model 2) that neighboring polities (as general Polity scores) do not foster an environment of civil war. When individual regime neighborhoods are tested, a more complex picture emerges (Table 4-models 3 and 4). Both autocratic and anocratic neighborhoods are significantly and positively associated with an increased risk of civil war. States surrounded by autocratic states are three times more likely to have a civil war over states in democratic neighborhoods. In anocratic neighborhoods, the risk of civil strife increases by a factor of 2.5 compared to odds ratios in a democratic neighborhood (see Table 4-model 3). More importantly, these regime neighborhoods alter the impact of GDP. When surrounded by democratic states, the effect of income on civil war onset is stable or flat; increasing income does not significantly alter the risk of civil war. In anocratic neighborhoods, increasing income has a significantly stronger role in lessening the risk of civil war. For a one unit increase in logged GDP, the risk of onset decreases by $34 \%$. The effect of increasing income in autocracies is slightly weaker, at a 33\% decrease in risk (see Figure 1 for illustration). 
Table 4: Neighboring Wars and Conflict Risk

\begin{tabular}{|c|c|c|c|c|}
\hline Variables & $\begin{array}{l}\text { Model } 1 \\
\text { Level } 2 \text { N:6820 } \\
\text { Level } 3 \text { N: } 161 \\
\text {-2ll: -983 } \\
\text { Dep Var: Onset }\end{array}$ & $\begin{array}{l}\text { Model } 2 \\
\text { Level } 2 \text { N:6820 } \\
\text { Level } 3 \text { N: } 161 \\
\text {-2ll: }-983 \\
\text { Dep Var: Onset }\end{array}$ & $\begin{array}{l}\text { Model } 3 \\
\text { Level } 2 \text { N:6820 } \\
\text { Level } 3 \text { N: } 161 \\
\text {-2ll: -974 } \\
\text { Dep Var: Onset }\end{array}$ & $\begin{array}{l}\text { Model } 4 \\
\text { Level } 2 \text { N:6820 } \\
\text { Level } 3 \text { N: } 161 \\
\text {-2LL: }-967 \\
\text { Dep V ar: Onset }\end{array}$ \\
\hline $\begin{array}{l}\text { All Neigh. } \\
\text { Wars }\end{array}$ & $.403(.154)^{* * *}$ & $.417(.155)^{* * *}$ & $.365(.152)^{* *}$ & $.337(.152)^{* *}$ \\
\hline LGDP & $-.283(.124)^{* *}$ & $-.246(.127)^{* *}$ & $.053(.150)$ & $.085(.139)$ \\
\hline Lpop & $.208(.06)^{* * *}$ & $.214(.06) * * *$ & $.213(.057) * * *$ & $.231(.058)^{* * *}$ \\
\hline Polity & $.013(.015)$ & $.025(.017)$ & $.053(.150)$ & \\
\hline Polity(2) & $-.000(.003)$ & $-.000(.003)$ & $-.002(.003)$ & \\
\hline Instability & $.906(.158) * * *$ & $.898(.158)$ & $.780(.160)^{* * *}$ & $.689(.163)^{* * *}$ \\
\hline Autocracy & & & & $-.039(.214)$ \\
\hline Anocracy & & & & $.509(.213)^{* *}$ \\
\hline Terrain & $.152(.068)^{* *}$ & $.157(.069)^{* *}$ & $.132(.064)^{* *}$ & $.122(.064)^{*}$ \\
\hline Oil & $.47(.222)^{* *}$ & $.456(.224)^{* *}$ & $.540(.231)^{* *}$ & $.454(.232)^{* *}$ \\
\hline Eth. Frac & $1.29(.35)^{* * *}$ & $1.27(.349)^{* * *}$ & $1.04(.343)^{* * *}$ & $1.00(.22)^{* *}$ \\
\hline $\begin{array}{l}\text { Neighbor } \\
\text { Polity }\end{array}$ & & $-.031(.022)$ & & \\
\hline $\begin{array}{l}\text { Neighbor } \\
\text { Polity (2) }\end{array}$ & & $.001(.003)$ & & \\
\hline Neigh_Auto & & & $1.04(.386)^{* *}$ & $.852(.382)^{* *}$ \\
\hline Neigh_Ano & & & $.908(.018)^{* *}$ & $.708(.355)^{* *}$ \\
\hline $\begin{array}{l}\text { N_Auto* } \\
\text { GDP }\end{array}$ & & & $-.446(.173)^{* *}$ & $-.443(.174) * *$ \\
\hline $\begin{array}{l}\text { N_Ano* } \\
\text { GDP }\end{array}$ & & & $-.432(.127)^{* *}$ & $-.409(.128)^{* * *}$ \\
\hline \multirow[t]{2}{*}{ Constant } & -6.58 & -6.73 & -6.47 & -7.40 \\
\hline & Variance Score \& \% & Variance Score \& \% & Variance Score \& \% & Variance Score \& \% \\
\hline Level Two & $.3357(9 \%)$ & $.3385(9 \%)$ & $.240(6 \%)$ & $.238(6 \%)$ \\
\hline
\end{tabular}


Figure 1: Risk Assessments by Neighborhood Regime Type \& GDP7

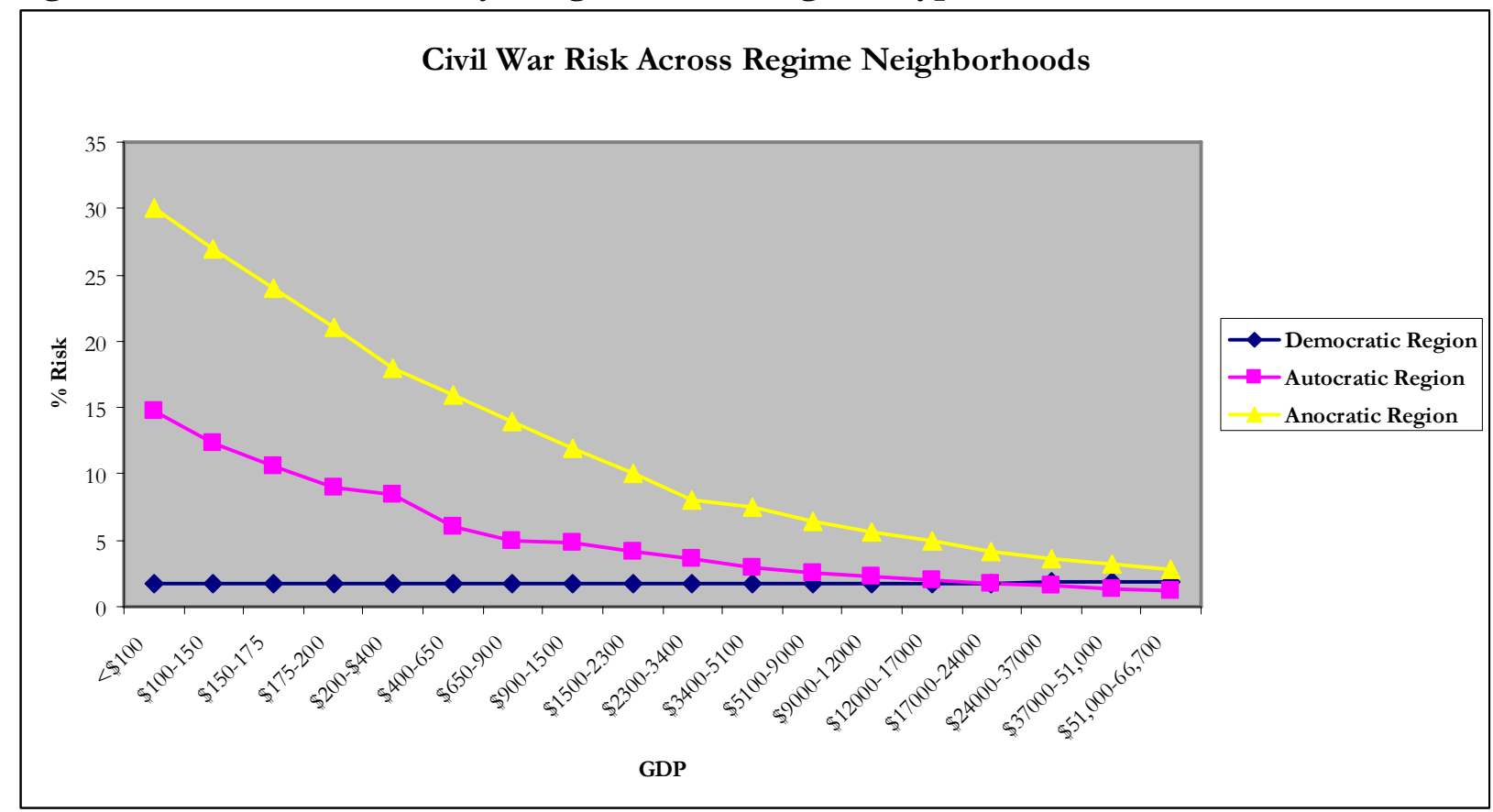

Model 4 demonstrates that the political character of states interacts differently with surrounding regions. Anocratic states in a democratic region have a significantly higher risk of civil war than democratic states in democratic regions. However, civil war risk in all states is heightened by belonging to an autocratic or anocratic region. Again, these interactive regional relationships alter the effect of GDP. Across three regime types (democratic, autocratic, and anocractic), the following patterns are clear: 1) civil war risk within democratic neighborhoods' hovers between $2-4 \%$ across all regime types (see Figures 2-4). This does not vary significantly across income, indicating that democratic neighborhoods have a peaceful effect on member states, regardless of domestic politics; 2) the slopes of war risk at increasing levels of income is similar across autocratic and anocratic neighborhoods, but the proportional decrease is significantly higher in anocratic neighborhoods, 3) anocratic states and regions are the most conflict prone, and anocratic states in anocratic regions

\footnotetext{
${ }^{7}$ These estimates for risk assessments by regime neighborhood were created by Clarify (Thoms, Wittenberg \& King, 2005) (see http://gking.harvard.edu/clarify/docs/clarify.html). Clarify does not create estimates with GLLAMM models, so these risks are based on logit models. Smaller differences remain, but the general trends are quite similar.
} 
have the highest average risk rate across all states. ${ }^{8}$ The variance associated with regime neighborhoods and income level decreases the variance explained across states from $9 \%$ to $6 \%$.

Figure 2 details conflict risk trajectories in democratic states. At low levels of income in unstable neighborhoods, the additional risk to democratic states is higher than that of an autocratic state in a democratic region; although the risks are quite similar (see Figure 3). At the median level of income, the impact of regime neighborhood converges.

\section{Figure 2: Conflict Risk in Democratic States across Regime Neighborhoods}

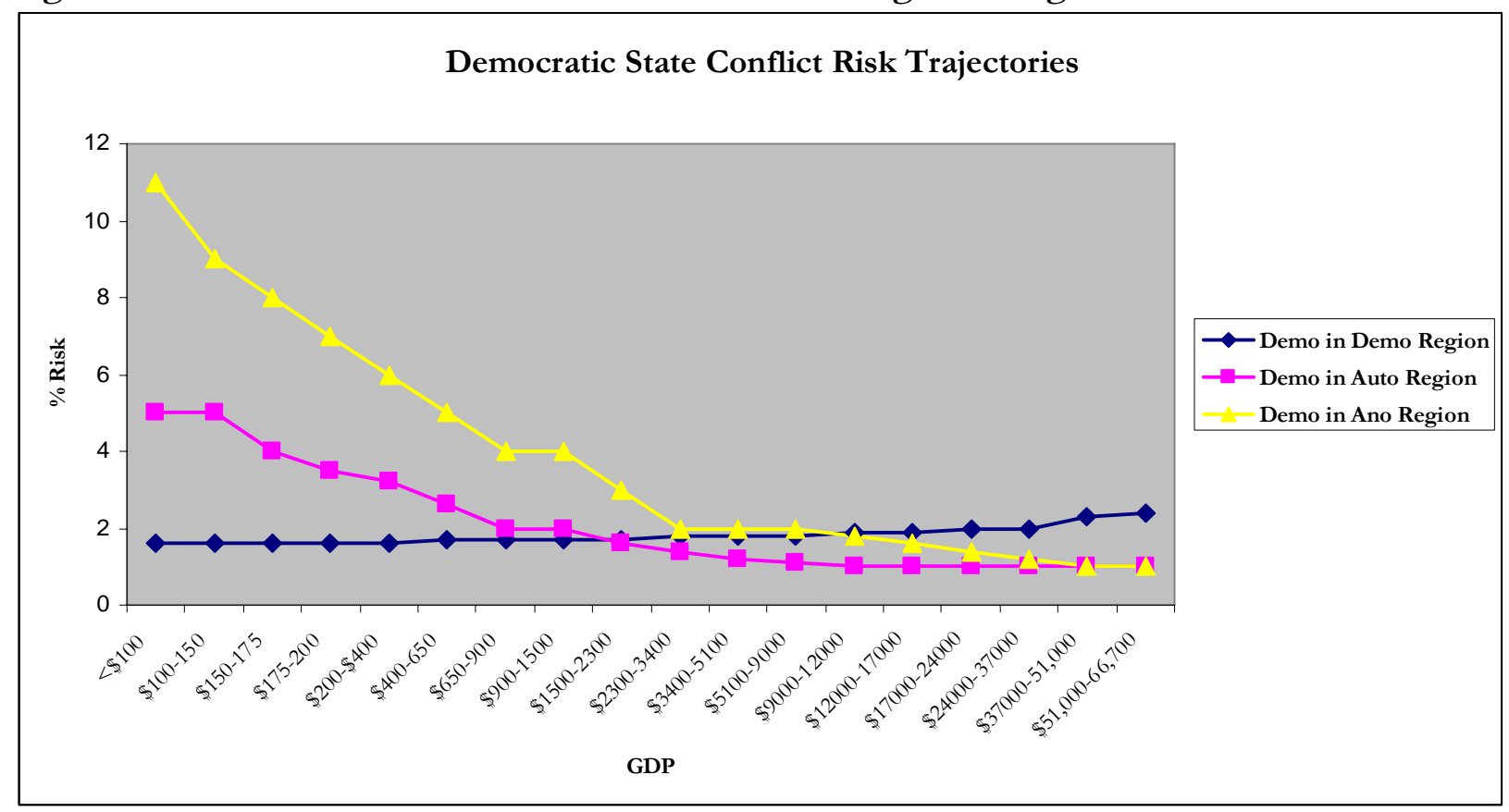

Figure 3 displays conflict risk trajectories in autocratic states. Although the risk across neighborhood does converge at the same position in both democratic and anocratic states, autocratic states are generally the least conflict prone at very low levels of income in unstable environments.

\footnotetext{
${ }^{8}$ Individual trajectories are based on model 4, with changes made for the clarify program. For each figure, the estimation is based on varying income, regime and regional type, a neighboring war, and all other variables at their mean.
} 
Figure 3 Conflict Risk in Autocratic States across Regime Neighborhoods

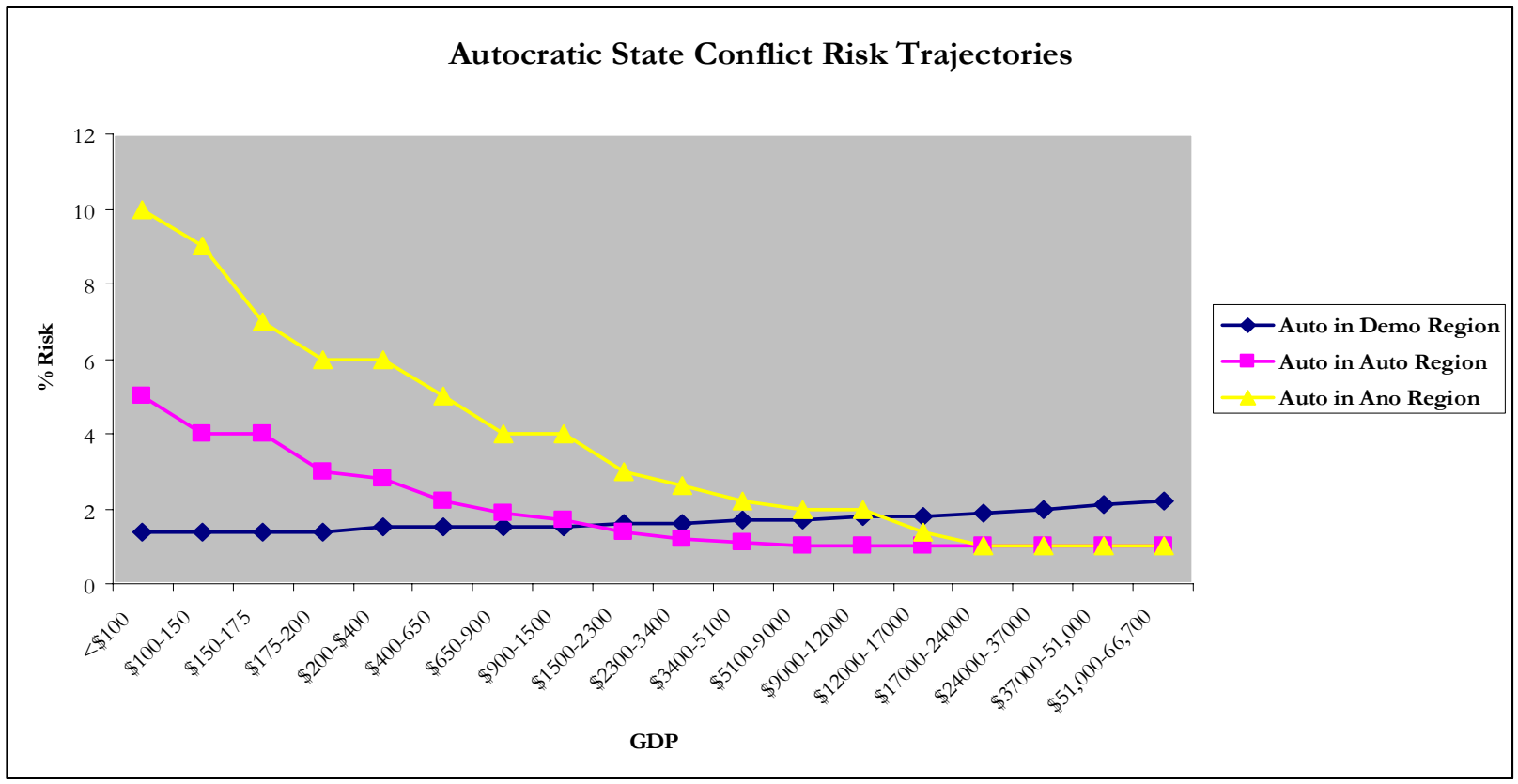

Figure 4 presents the highest conflict risk category of anocratic states across regions. Although, other types of states also have their highest risks in anocratic regions. Again, there is a general convergence at the income scale's mid point (1.2-1.6). If incomes are doubled from the lowest point, the risk of conflict is halved.

Figure 4 Conflict Risk in Anocratic States across Regime Neighborhoods

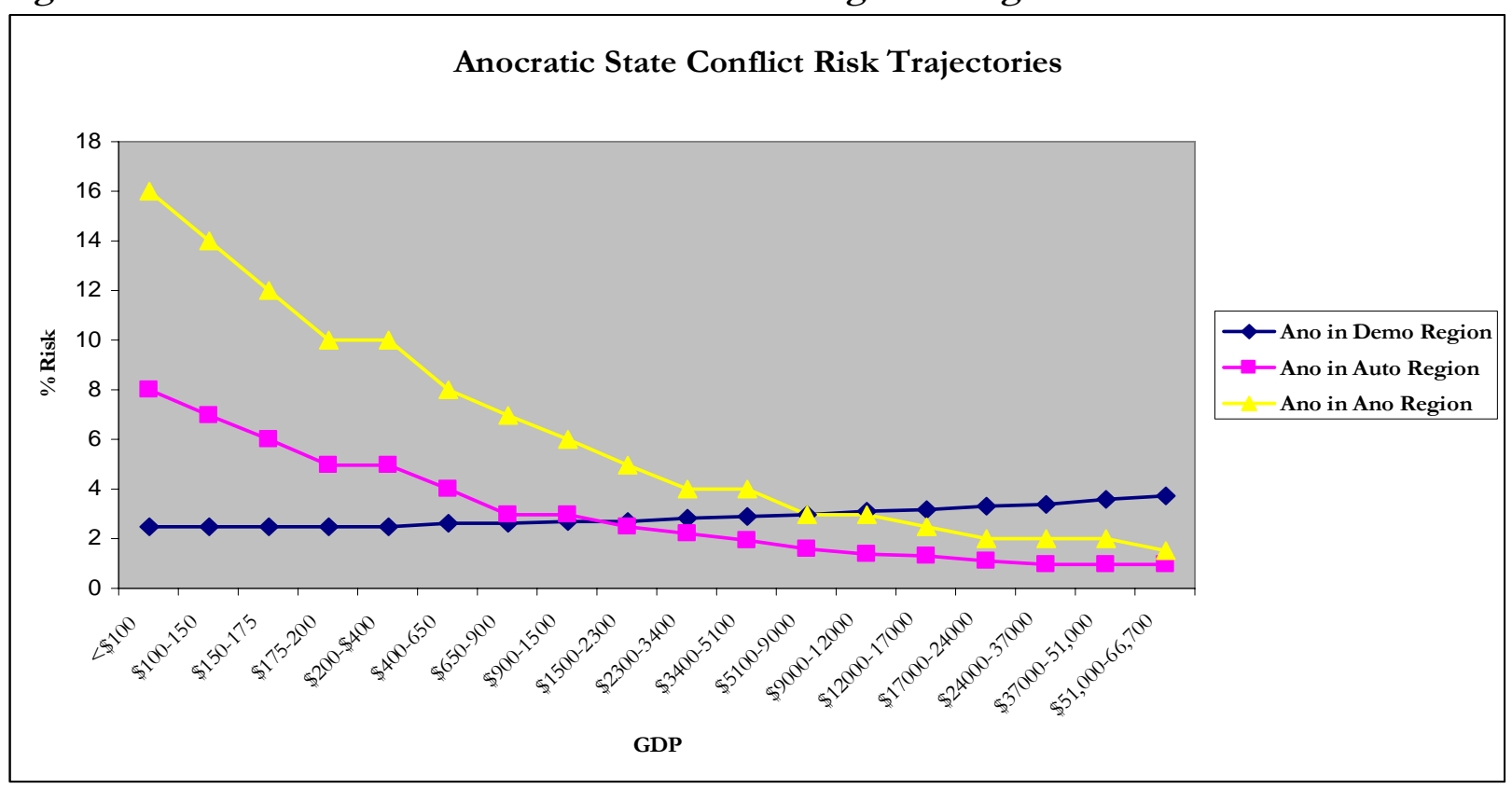




\subsection{Recurrence}

In empty multilevel models of instability, $41 \%$ of the natural variability of recurrence is due to variation between states. Basic logit models for this sample disqualified a number of independent variables found significant in models for all civil wars. These effects are confirmed by Multilevel models; domestically, only instability, population, ethnic fractionalization, and anocracy are positively and significantly related to conflict recurrence (see Table 5). Neighboring anocracies and income interacted with autocratic neighborhoods are weakly related to higher risks of civil conflict at particular income points. Overall, these models are not particularly good predictors of civil war recurrence. Since recurrence is approximately $40 \%$ of all civil wars in the sample, models 1-4 are perhaps only explaining correlates to a portion of all wars.

There is a remaining 13\%-17\% of unexplained country level heterogeneity across models 57. States differ significantly in their recurrence risk determinants. Models 5-7 are also run controlling for select regions (Africa, South Asia, etc); these controls are highly insignificant. Because the model is a poor fit, and considerable heterogeneity, figures such as those for the models 1-4 do not display significant differences across regime neighborhoods.

Table 5: Recurrence Models

\begin{tabular}{|c|c|c|c|}
\hline Variables & $\begin{array}{l}\text { Model } 5 \\
\text { Level } 1 \text { N:6820 } \\
\text { Level } 2 \text { N: } 161 \\
\text {-2ll: }-465 \\
\text { Dep Var: Recur }\end{array}$ & $\begin{array}{l}\text { Model } 6 \\
\text { Level } 1 \text { N:6820 } \\
\text { Level } 2 \text { N: } 161 \\
\text {-2ll: }-461 \\
\text { Dep V ar: Recur }\end{array}$ & $\begin{array}{l}\text { Model } 7 \\
\text { Level } 1 \text { N:6820 } \\
\text { Level } 2 \text { N: } 161 \\
\text {-2ll: -459 } \\
\text { Dep V ar: Recur }\end{array}$ \\
\hline All Neigh.Wars & $.345(.238)$ & $.309(.235)$ & $.292(.233)$ \\
\hline Instability & $1.00(.234)^{* * *}$ & $.961(.236)^{* * *}$ & $.852(.239)^{* * *}$ \\
\hline LGDP & $-.117(.192)$ & $.141(.238)$ & $.068(.22)$ \\
\hline Lpop & $.273(.083)^{* * *}$ & $.257(.081)^{* * *}$ & $.267(.081)^{* * *}$ \\
\hline Terrain & $.077(.096)$ & $.060(.093)$ & $.052(.092)$ \\
\hline Oil & $.362(.318)$ & $.526(.321)$ & $.495(.318)$ \\
\hline Eth. Frac & $1.55(.507)^{* *}$ & $1.43(.501)^{* *}$ & $1.34(.494)^{* *}$ \\
\hline Polity & $-.0013(.026)$ & $-.0125(.025)$ & \\
\hline Polity(2) & $-.0044(.0055)$ & $-.004(.005)$ & \\
\hline Autocracy & & & $.080(.333)$ \\
\hline
\end{tabular}




\begin{tabular}{|c|c|c|c|}
\hline Variables & $\begin{array}{l}\text { Model } 5 \\
\text { Level } 1 \text { N:6820 } \\
\text { Level } 2 \text { N: } 161 \\
\text {-2ll: }-465 \\
\text { Dep Var: Recur }\end{array}$ & $\begin{array}{l}\text { Model } 6 \\
\text { Level } 1 \text { N:6820 } \\
\text { Level } 2 \text { N: } 161 \\
\text {-2ll: }-461 \\
\text { Dep Var: Recur }\end{array}$ & $\begin{array}{l}\text { Model } 7 \\
\text { Level } 1 \text { N:6820 } \\
\text { Level } 2 \text { N: } 161 \\
-2 l l:-459 \\
\text { Dep Var: Recur }\end{array}$ \\
\hline Anocracy & & & $.607(.325)^{*}$ \\
\hline $\begin{array}{l}\text { Neighbor } \\
\text { Polity }\end{array}$ & $-.0093(.036)$ & & \\
\hline $\begin{array}{l}\text { Neighbor } \\
\text { Polity (2) }\end{array}$ & $-.006(.005)$ & & \\
\hline Neigh_Auto & & $.373(.653)$ & $.398(.648)$ \\
\hline Neigh_Ano & & $.980(.580)^{*}$ & $.911(.583)$ \\
\hline $\begin{array}{l}\text { N_Auto* } \\
\text { GDP }\end{array}$ & & $-.623(.319)^{*}$ & $-.601(.324)^{*}$ \\
\hline $\begin{array}{l}\text { N_Ano* } \\
\text { GDP }\end{array}$ & & $-.264(.187)$ & $-.226(.186)$ \\
\hline \multirow[t]{2}{*}{ Constant } & -7.96 & -8.614 & -8.96 \\
\hline & $\begin{array}{l}\text { Variance Score \& } \\
\%\end{array}$ & $\begin{array}{l}\text { Variance Score \& } \\
\%\end{array}$ & $\begin{array}{l}\text { Variance Score \& } \\
\%\end{array}$ \\
\hline Level Two & $.337(17 \%)$ & $.266(14 \%)$ & $.237(13 \%)$ \\
\hline
\end{tabular}

Hypothesis one is clearly upheld. Neighboring civil wars do foster an environment of increased risk for civil conflict within a state. This holds across war size, although surprisingly, smaller wars have a stronger influence, possibly due to the increased number of smaller wars. Hypotheses two and three are supported. Different neighborhoods have strikingly different conflict trajectories. In addition, interactions between individual states and regions alter conflict trajectories across income levels. The influences of neighborhood political institutions are contingent upon a state's development level, and vice versa, the influence of income is related to the surrounding political context. Democratic neighborhoods have a stabilizing influence; the effects of democracy at any level of income are flat and discourage civil war within a state. The creation of such neighborhoods ensures that income level of a state is no longer the dominant factor in civil war onset. Autocratic and anocratic neighborhoods do increase the risk of civil war onset within a state; this risk is significantly mitigated by an increasing GDP within a state. This income effect is slightly more powerful in autocratic 
neighborhoods.

With regard to recurrence, the models specified here found domestic determinants, such as population and instability are very critical to states in a post-war environment. However, neither domestic nor surrounding polity scores for states are found to influence risk. When distinguished by regime type, only anocratic states have almost three times the risk of returning to war than a democratic state (which is extremely low). Income does influence the effect of recurrence in autocratic neighborhoods, but again the additional risk is quite small. Overall, hypothesis four is only partially accepted; it certainly does not display the regime neighborhood variation evident in the total civil war sample.

\subsection{Discussion}

The aim of this paper is to first identity the effects of neighboring regimes and neighboring wars on domestic civil war risk and conflict recurrence, and second to detect characteristics of states which are particularly affected by their neighbors. In relation to the first, neighboring wars do increase the risk of civil war within states with an average risk increase of $39 \%$. This risk is dependent on the political milieu of the state at hand. Domestic characteristics can moderate the increased risk from neighbors, particularly increasing income levels. However, regional characteristics can moderate domestic characteristics, especially democratic regional effects. If a state is surrounded by stable, developed democracies the risk of conflict, regardless of income, never increases past 4\%. The risk profiles for all states in autocratic or anocratic regions are highly dependent on income level. Hence, neighboring regimes types do alter the context within which domestic upset occurs. Their effects are conditional on development levels, yet the analysis clearly pointed to the effects exceptionally risk prone anocratic, or mixed regime, neighborhoods have on domestic regime stability.

This conclusion is certainly not as strong with regard to conflict recurrence, where the model found weak support that democratic regions are more stable and anocratic neighborhoods less so. However, the risk profiles were extremely low due to the model specifications. Neither the political character of the state surrounding regions does not, at this time, appear to strongly affect the risk of conflict recurrence.

With regard to the second point, differences in internal and neighborhood characteristics of states explain almost one sixth of the global variance in recurrence rates, and between $6-9 \%$ of the 
variance in civil war onset across states. This reinforces both the well established importance of country year characteristics and the often unnoted importance of states as distinct units of analysis.

It is clear from this study that neighborhoods matter; neighboring wars contribute considerable risk to civil war onset and neighborhood political attributes can mitigate or add to the risk, although this relationship is contingent upon income level in all but democratic neighborhoods. That income is more important in particular political surroundings is a unique finding of this study. Such a conclusion contributes to understanding the traps that low income states are in-a poverty trap, as elaborated by Jeffrey Sachs (2005), but also a related political trap. The overwhelming negative influence of political disorder may be as important in limiting the economic opportunities available to unstable states.

Such traps, whether economic or political, are phenomena of already weak states. It is clear from the results presented here that states most prone to civil wars are also most prone to being adversely influenced by their neighbors. The diffusion of political disorder and civil wars creates a 'double jeopardy' situation. These disparities across states are not due to variance in economic, political or social situation controlled for in the models presented here, but different positive or adverse patterns of regional influence.

In the most recent iteration of Marshall and Gurr's State failure project, they identify ten 'neighborhoods' of political relevance (see http://members.aol.com/cspmgm/conflict.htm). They also find that democracy is increasing over time relative to autocracy. Democracy and autocracy have inverse relationships to each other which seem to be separate from anocratic trends. As global democracy is rising this should, by all accounts, lead to more inter-state and intra-state peace. Although new and transitional democratic internal peace is unstable, functioning democracies are more peaceful internally and externally. Research presented here is unique in its contribution regarding how regime type as a significant development indicator, which in turn is salient in determining the risk of civil war across states. This paper contributes to a growing body of literature acknowledging the importance on regional context in the differential development across states. 


\subsection{Bibliography}

Alberto Alesina and Enrico Spolaore, 2003. The Size of Nations. Cambridge: MIT Press.

Atlas Narodov Mira. Glavnoe Upravlenie Geodezii Kartografii. ATLAS MIRA WORLD ATLAS]. Moscow, 1964

Benson, Michelle and Jacek Kugler, 1998. "Power Parity, Democracy, and the Severity of Internal Violence." Journal of Conflict Resolution. 42(2): 196-209.

Boardman, Jason, 2003. Multilevel Modelling Handout. Boulder, Colorado, Department of Sociology, University of Colorado.

Boardman, Jason D., and Jarron Saint Onge, 2005."Neighborhoods and Adolescent Development." Children, Youth, and Environments 15(1):138-164.

Cederman, Lars-Erik \& Kristian Skrede Gleditsch, 2004. "Conquest and Regime Change: An Evolutionary Model of the Spread of Democracy and Peace." International Studies Quarterly 48(3): 603-629.

Cohen, Saul B., 2003. Geopolitics of the World System. New York, Rowman and Littlefield.

Collier, Paul and Anke Hoeffler, 2002. "Aid, Policy and Peace." Defense and Peace Economics 13 (6): 435-450.

Collier, Paul and Anke Hoeffler, 2004. "The Challenge of Reducing the Global Incidence of Civil War." Copenhagen Consensus, Copenhagen.

Collier, Paul, L. Elliot, et al., 2003. Breaking the Conflict Trap. World Bank and Oxford University Press.

Doyle, Michael and Nicholas Sambanis, 2000. "International Peacebuilding: a Theoretical and Quantitative Analysis.” American Political Science Review, 94(4): 779-802.

Elbadawi, Ibrahim A., 2001. "Civil Wars and Poverty: The Role of External Interventions, Political Rights and Economic Growth.” Unpublished paper, World Bank from http://econ.worldbank.org/programs/conflict/library/doc?id = 13208

Fearon, James and David Laitin, 2003. "Ethnicity, Insurgency, and Civil War." American Political Science Review 97(1): 75-90.

Fearon, James and David Laitin, 2003. "Additional Tables for Ethnicity, Insurgency, and Civil War." Available from http://www.stanford.edu/group/ethnic/ 
Gates, Scott, 2002. “The Microfoundations of Rebellion.” Journal of Conflict Resolution 46(1):111130.

Gleditsch, Kristian Skrede \& Kyle Beardsley, 2004. "Nosy Neighbors: Third-Party Actors in Central American Conflicts." Journal of Conflict Resolution 46:379-402.

Gleditsch, Kristian Skrede, 2002. All International Politics is Local: The Diffusion of Conflict, Integration, and Democratization. Ann Arbor, MI: University of Michigan Press.

Gleditsch, Kristian Skrede \& Michael D. Ward, 2001. "Measuring Space: A Minimum Distance Database and Applications to International Studies." Journal of Peace Research 38:739-58.

Gleditsch, Kristian S. \& Michael D. Ward, 2002. "Peace and War in Time and Space: The Role of Democratization." International Studies Quarterly 44:1-29.

Hegre, Håvard, Tanja Ellingsen, Scott Gates \& Nils Petter Gleditsch, 2001. Toward A Democratic Civil Peace? Democracy, Political Change, and Civil War 1816-1992." American Political Science Review 95(1):16-33.

Hegre, Håvard \& Clionadh Raleigh, 2005. 'Population Size, Concentration, and Civil War: a Geographically Disaggregated Analysis', presented at the Summer Meeting of the Polarization and Conflict Project, Konstanz, 2-5 June.

Huntington, Samuel, 1996. The Clash of Civilizations and the Remaking of the World Order. New York, Touchstone.

Lake, David and David Rothchild, 1998. The International Spread of Ethnic Conflict. Princeton, New Jersey, Princeton University Press.

Murdoch, J. and T. Sandler, 2002. "Economic Growth, Civil Wars, and Spatial Spillovers." Journal of Conflict Resolution 46(1): 91-110.

Mansfield, E.D. and J. Snyder, 2002. "Democratic Transitions, Institutional Strength, and War." International Organization, Spring: 297-337.

Nkurunziza, Janvier and Floribert Ngaruko, 2002. "Explaining Growth in Burundi: 1960-2000."

Centre for the Study of African Economies Working Paper Series. Working Paper 162.

O'Loughlin, J., M. D. Ward, et al., 1998. “The Diffusion of Democracy, 1946-1994.” Annals, Association of American Geographers 88(4): 545-574.

Sachs, Jeffrey, 2005. The Poverty Trap. Penguin, New York. 
Salehyan, Idean and Kristian Skrede Gleditsch, 2004. Refugee Flows and the Spread of Civil War. Paper Present at the 100th Annual Meeting of the American Political Science Association, Chicago, IL, 2-5 September 2-5.

Sambanis, Nicholas, 2001. "Do Ethnic and Non-Ethnic Civil Wars Have the Same Causes? A Theoretical and Empirical Inquiry (Part 1)." Journal of Conflict Resolution 45 (3): 259-82.

Sambanis, Nicholas, 2002. "A Review of Recent Advances and Future Directions in the Quantitative Literature on Civil War.” Defense and Peace Economics, 13(3): 215-243.

Sambanis, Nicholas, 2003. "Using Case Studies to Expand the Theory of Civil War." Conflict Prevention and Reconstruction Working Paper No. 5 (150pp). May 2003. [http://lnweb18.worldbank.org/ESSD/essd.nsf/CPR/WP5]

Sniders, A. B. and R. Bosker, 1999. Multilevel Analysis. London, Sage.

Starr, Harvey, 1991. "Diffusion Approaches to the Spread of Democracy." Journal of Conflict Resolution 35(2): 356-81.

Rabe-Hesketh, S., Skrondal, A. and Pickles, A. (2004). Generalized multilevel structural equation modelling. Psychometrika 69 (2): 167-190.

Walter, Barbara, 2004. Does Conflict Beget Conflict? Explaining Recurring Civil War.” Journal of Peace Research, 41(3):371-388.

Woodwell, Doug, 2004. "Unwelcome Neighbors: Shared Ethnicity and International Conflict during the Cold War." International Studies Quarterly 48(1):197-233. 


\section{Appendix}

Table 3.2: Summary Statistics for Dependent and Independent Variables

Variable Observations

Mean

Std. Dev

Min

$\operatorname{Max}$

Summary Statistics of State Core Variables

Log GDP

Log Pop

6818

6820

Polity

0.7685

9.073

0.854

1.452

$-0.3143$

6.257

56.17

24.59

Rough Terr.

6818

2.172

1.45

6820

6820

Instability

6820

Ethnic Frac

6820

0.13

0.337

0.126

0.332

0.46

0.269

Uppsala Onset

6820

0.036

0.188

$\begin{array}{ll}-2.8785 & 4.2\end{array}$

5.4

4.2

14.055

$-10 \quad 10$

$0 \quad 100$

$0 \quad 4.55$

$0 \quad 1$

$0 \quad 1$

$0.00199 \quad 1$

Summary Statistics of Neighboring and Neighborhood Core Variables

Neighbor_Wars

Big War

Small War

Neigh_Demo

Neigh_Auto

Neigh_Ano

Neigh_Instabi

Ano_Income

Auto_Income
6820

6820

6820

6820

6820

6820

6820

3820

3820
0.1596

0.235

0.1587

0.259

0.5818

0.361

0.3822

0.1141
0.36

0.424

0.336

0.438

0.493

0.48

0.79

0.58

0

1

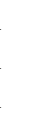

